\title{
O ACOLHIMENTO DE REFUGIADOS SÍRIOS E O DISCURSO ADOTADO INTERNACIONALMENTE: UMA ANÁLISE COMPARATIVA ENTRE O BRASIL E A FRANÇA
}

\author{
HOSTING OF SYRIAN REFUGEES AND THE DISCOURSE ADOPTED INTERNATIONALLY: \\ A COMPARATIVE ANALYSES OF BRAZIL AND FRANCE
}

\section{Gabriela Santos da Silva}

Doutoranda e Mestra em Estudos Estratégicos Internacionais pela Universidade Federal do Rio Grande do Sul e Graduada em Relações Internacionais pela Universidade Federal de Santa Catarina (UFSC).

E-mail: silva.gaabii@gmail.com

\section{Thaís Dutra Fernández}

\begin{abstract}
Mestra em Human Rights and Humanitarian Action pelo Instituto de Estudos Políticos de Paris (Sciences Po) e Mestra em Estudos Estratégicos Internacionais pela Universidade Federal do Rio Grande do Sul (UFRGS). Bacharel em Direito pela Universidade Federal de Minas Gerais (UFMG) e em Relações Internacionais pela Pontifícia Universidade Católica de Minas Gerais (PUCMinas). E-mail: thais.dutrafernandez@sciencespo.fr
\end{abstract}

Recebido em: 19/12/2018

Aprovado em: 27/06/2019

RESUMO: O conflito armado na Síria teve início em 2011 e, desde então, tem gerado consequências em termos de grandes deslocamentos humanos. Desde 2013, o Brasil concede visto especial às vítimas desse conflito, enquanto a França busca facilitar a análise das demandas de asilo no âmbito da União Europeia, estabelecendo cotas. Em 2018, a Síria figurava em terceiro lugar na lista de países que mais solicitaram refúgio no mundo, sendo igualmente uma das nacionalidades que mais requeria tanto no Brasil, quanto na França. Este artigo pretende realizar estudo comparado da legislação e das políticas de integração, ao analisar como ocorre a entrada dos refugiados sírios no Brasil e na França e sua conformação ao discurso desses países em fóruns, conferências e encontros internacionais relacionados ao tema de migrações ou em organizações multilaterais, como as Nações Unidas. A análise da conformidade entre o discurso e a prática é necessária para verificar se os países têm cumprido com as promessas no que diz respeito ao tratamento dos refugiados - principalmente os sírios.

Palavras-chave: Análise comparativa. Refugiados sírios. Brasil. França.

ABSTRACT: The armed conflict in Syria began in 2011 and since then there has been consequences in terms of major human displacements. Since 2013, Brazil has granted special visas to victims of this conflict; while France seeks to advance analyses of asylum seek within the European Union, by establishing a quota. In 2018, Syria was placed third in the list of countries that most requested asylum in the world. Syrians were amongst the nationalities that most requested asylum in Brazil, as well as in France. This article intends to do a comparative study by analyzing

Revista de Direito Brasileira | Florianópolis, SC | v. 26 | n. 10 | p. 66-83 | Mai./Ago. 2020 
how the hosting of Syrian refugees occurs both in brazil and France - in terms of legislation and of integration policies. We will also analyze how it matches the rhetoric adopted by these countries in international forums, meetings, and conferences related to migration; or in multilateral organizations, such as the United Nations. The analysis of such confirmation is necessary in order to attest if both countries are complying with their international rhetoric with regards to refugees especially the Syrians.

Keywords: Comparative analysis. Syrian Refugees. Brazil. France.

SUMÁRIO: Introdução. 1 O Brasil frente aos refugiados sírios. 1.1 A legislação brasileira de refúgio. 1.2 O Discurso Internacional Brasileiro sobre o tema dos Refugiados Sírios. 1.3 A Percepção dos Refugiados Sírios No Brasil. 2 A França frente aos refugiados sírios. 2.1 A legislação europeia de refúgio. 2.2 O Discurso Internacional Francês sobre o tema dos Refugiados Sírios. 2.3 A percepção dos refugiados sírios na França. Conclusão. Referências.

\section{INTRODUÇÃO}

A Guerra da Síria é um grande desafio para o Sistema Internacional. Esse conflito que, no ano de 2019, completa oito anos, sofreu o efeito de transbordamento, atingindo grande parte da região do Oriente Médio e envolvendo outros países - seja por meio de posicionamentos em relação às partes envolvidas no conflito, seja em função do acolhimento do alto número de refugiados que continuam a se deslocar para países vizinhos. Ao contrário do que é constantemente enfatizado pela mídia, a maior parte das pessoas que atravessa fronteiras para fugir do conflito no país se instala em países vizinhos, por conta, principalmente, da falta de condições econômicas para emigrar para países mais geograficamente mais distantes.

O objetivo deste artigo é o de comparar as legislações e o discurso reproduzido internacionalmente em relação às políticas de integração e à percepção sobre os refugiados sírios em dois países: o Brasil e a França. A escolha destes países ocorre em decorrência da sua diferença geográfica e do fato de serem países relevantes no recebimento de refugiados sírios na América do Sul e na Europa, respectivamente. O Brasil, desde 2013, concede visto especial para os sírios que tenham sido "forçosamente deslocados por conta do conflito armado na República Árabe Síria" (CONARE, 2013). Já a França se envolve na questão como Estado membro da União Europeia, onde foi estabelecida cota para o acolhimento desses indivíduos. Em 2018, a Síria figurava em terceira posição na lista de países que mais solicitaram refúgio no mundo - figurando também como uma das nacionalidades que mais realiza solicitações no Brasil e na França.

Em 2016 as demandas realizadas por nacionais sírios foram as mais deferidas, dada a proporção e relevância que o conflito neste país tomou internacionalmente. Com uma demanda considerável de refúgio de indivíduos sírios no Brasil e na França, é possível notar que iniciativas - percebidas através de Resoluções ou de cotas - também são criadas. Torna-se, portanto, academicamente relevante analisar o discurso adotado internacionalmente por esses países, como forma de verificar sua conformidade com as legislações internas referentes ao acolhimento desses indivíduos e com a percepção que os Estados brasileiro e francês têm após a entrada desses indivíduos nos países. Dessa forma, busca-se investigar se há conformidade entre o que se enuncia em discursos e o que consta na legislação, de um lado, e a realidade vivenciada pelos refugiados, de outro.

A fim de comparar, nestes dois países, a diferença entre o que é manifestado internacionalmente em discursos e a realidade que os refugiados sírios enfrentam, cabe utilizar a análise qualitativa de documentos e a análise de discursos como metodologia. A análise qualitativa de documentos permite a investigação da legislação que versa sobre a questão dos refugiados nos dois países e as diretrizes impostas internacionalmente sobre o assunto. A Convenção das Nações 
Unidas relativa ao Estatuto dos Refugiados - Convenção de Genebra de 1951 - e a Declaração de Cartagena de 1984 são exemplos de documentos oficiais discutidos e aceitos internacionalmente e que apesar de não serem vinculantes, estabelecem as bases de acolhimento dos refugiados para seus signatários. No Brasil, ademais destes documentos, leis oficiais e resoluções propostas pelo Comitê Nacional dos Refugiados (CONARE) são levadas em consideração. Já na França, além da legislação nacional, representada pelo Code de l'entrée et du séjour des étrangers et du droit d'asile (CESEDA), deve-se considerar a Convenção de Dublin de 1990 (e suas adaptações ao longo dos anos), legislação comum entre os membros da União Europeia, além de discussões que acontecem na Comissão Europeia sobre questões das demandas por refúgio.

Uma vez que os discursos, de acordo com Norman Fairclough (2003), são formas de representar aspectos do mundo - processos, relações, estruturas, pensamentos, sentimentos, crenças, entre outros -, eles serão distintos uns dos outros. Isso ocorre porque aqueles que proferem os discursos têm perspectivas distintas sobre o mundo, as quais também dependem da sua posição na sociedade. Muitas vezes estas posições podem, até mesmo, abrigar certas opiniões nos discursos de forma a projetar uma alteração na realidade para determinada direção que favoreça aquele que pronuncia o discurso - e, possivelmente, um grupo de pessoas. Isso pode ser traduzido nos discursos proferidos por governantes, uma vez que, ao proferirem suas mensagens, não tomam mais a forma de pessoa física e, sim, de representantes daquele território e daqueles cidadãos que governam.

Neste sentido, no intuito de assimilar a mensagem oficial do Brasil, este artigo buscou discursos de representantes brasileiros - Presidente e Ministro - uma vez que estes forneceriam a percepção do Estado brasileiro no que diz respeito ao tema de refúgio - principalmente, dos sírios. A pesquisa foi realizada na página do Ministério das Relações Exteriores, tendo como palavraschave "Síria" e "sírio" e os eventos foram selecionados pelo grau de importância - a Conferência Internacional de Apoio à Síria e Região e a Reunião de Alto Nível sobre Grandes Movimentos de Refugiados e Migrantes, por exemplo, foram os dois eventos mais relevantes na análise do discurso, por terem a centralidade do tema de refúgio e da questão síria.

Já em relação ao discurso francês, é possível perceber a construção de posicionamentos através das figuras dos Presidentes François Hollande e Emmanuel Macron e do Ministro das Relações Exteriores Laurent Fabius. Na página France Diplomatie, assim como o que foi feito na página do Ministério das Relações Exteriores do Brasil, utilizaram-se os termos "Síria" e "sírio" para verificar os discursos que foram proferidos sobre o tema. A escolha de discursos dos presidentes e do Ministro das Relações Exteriores ocorre pelo fato de que estes são os atores que representam o posicionamento da França sobre o assunto.

Além disso, engajamentos oficiais tomados por organismos que lidam com a questão, como o CONARE, o Office de protection des réfugiés et apatrides (OFPRA) ou o Alto Comissário Assistente para Proteção da Agência da ONU para Refugiados (ACNUR), também são levados em consideração, uma vez que indicam o posicionamento de organismos brasileiros oficiais brasileiros e franceses acerca do tema.

Para comparar os discursos e as legislações com a realidade percebida pelos refugiados sírios nestes dois países, é necessário investigar a percepção destes após o aceite da demanda de refúgio e a entrada no Brasil e na França. Essa investigação foi realizada por meio da análise de notícias jornalísticas, onde entrevistas com refugiados sírios são feitas e, também, onde é possível perceber a real situação em que se encontram nestes países. Dessa forma, é possível, realmente, verificar se a realidade faz jus às promessas mantidas internacionalmente.

\section{O BRASIL FRENTE AOS REFUGIADOS SÍRIOS}

O Brasil é o país que mais recebe solicitações de refúgio de nacionais sírios no continente americano. Sendo assim, esta seção busca compreender qual a legislação que rege essas demandas e sua conformidade não apenas com o discurso internacional adotado pelo país, como também

Revista de Direito Brasileira | Florianópolis, SC | v. 26 | n. 10 | p. 66-83 | Mai./Ago. 2020 
pelas políticas de acolhida e de integração dessas pessoas - que podem ser notadas por meio da percepção delas sobre a realidade que vivem no Brasil.

\subsection{A legislação brasileira de refúgio}

O ano de 1997 representa o início da adoção de uma legislação mais protetiva e humanista em relação ao recebimento e tratamento das pessoas refugiadas. Ao definir quais as pessoas elegíveis, o texto da Lei 9474/97 incorporou as características da Convenção de Genebra de $1951^{1}$, de que refugiado seria aquela pessoa que

(...) temendo ser perseguida por motivos de raça, religião, nacionalidade, grupo social ou opiniões políticas, se encontra fora do país de sua nacionalidade e que não pode ou, em virtude desse temor, não quer valer-se da proteção desse país, ou que, se não tem nacionalidade e se encontra fora do país no qual tinha sua residência habitual em consequência de tais acontecimentos, não pode ou, devido ao referido temor, não quer voltar a ele (CONVENÇÃO DE GENEBRA, 1951).

No entanto, referido diploma legal inovou ao também adotar o conceito ampliado de refugiado presente na Declaração de Cartagena de $1984^{2}$ e acordado por países latino americanos. Sendo assim, além do estabelecido na Convenção de Genebra de 1951 e em seu Protocolo Adicional de 1967, que retirou a limitação geográfica presente na Convenção, refugiados também podem ser

(...) pessoas que tenham fugido dos seus países porque a sua vida, segurança ou liberdade tenham sido ameaçadas pela violência generalizada, a agressão estrangeira, os conflitos internos, a violação maciça dos direitos humanos ou outras circunstâncias que tenham perturbado gravemente a ordem pública (DECLARAÇÃO DE CARTAGENA, 1984).

Conforme estabelece o artigo $7^{\circ}$ da Lei 9474/1997, é necessário que o imigrante esteja em território nacional e expresse seu interesse de solicitar o reconhecimento como refugiado frente à autoridade migratória de fronteira. Por isso, dada a alta burocracia para se conseguir reunir os documentos necessários para a solicitação do visto, aliada ao fato de que o visto é uma mera expectativa de direito (art. 6 da Lei 13.445/2017), a vinda e a recepção de pessoas que necessitam dessa forma de proteção no Brasil poderia ser dificultosa.

Em razão dessas dificuldades e das graves e generalizadas violações de direitos humanos perpetradas na República Árabe da Síria, o CONARE editou, em 2013, a Resolução Normativa 17, que visava a facilitação da concessão de visto a nacionais daquele país, desde que manifestassem sua vontade de buscar refúgio no Brasil. Por mais importante que seja a edição dessa Resolução Normativa, ela se trata de política migratória de governo ao invés de ter sido planejada como política de Estado, na medida em que tem validade de dois anos e necessita ter seu prazo repetidamente prorrogado.

Dessa forma, desde 2013, consulados e embaixadas brasileiras localizados no Oriente Médio têm emitido vistos especiais em processos mais simplificados para permitir que os

\footnotetext{
1 “Aprovada em 1951 devido ao grande número de refugiados europeus no pós-Guerra, convenção é principal base jurídica internacional sobre a proteção a pessoas em fuga por perseguição racial, religiosa ou política" (DW, 2017, $\mathrm{s} / \mathrm{p})$.

2 “A Declaração de Cartagena, elaborada em 1984, tem como foco definir parâmetros para a conceituação, a proteção e a superação dos obstáculos enfrentados por essas pessoas. Foi a partir da Declaração de Cartagena que a definição de refugiado estabelecida na Convenção da ONU, de 1951, pode ter uma interpretação expandida (...) incluindo as graves violações aos direitos humanos" (CAMINHOS DO REFÚGIO, 2014, s/p).
}

Revista de Direito Brasileira | Florianópolis, SC | v. 26 | n. 10 | p. 66-83 | Mai./Ago. 2020 
sobreviventes da guerra síria possam viajar para Brasil e, somente depois de chegar ao país, realizar o pedido de refúgio. Esta emissão de vistos para os solicitantes se concentra, principalmente, nas embaixadas brasileiras em Beirute, no Líbano, em Amã, na Jordânia e em Istambul, na Turquia. Isso porque a representação diplomática em Damasco, na Síria, foi fechada em 2012, por motivos de segurança (BARRUCHO, 2015).

Considerada referência em termos de direitos humanos, a lei 9474/1997, somada à Resolução Normativa 18 do CONARE de 2014, que buscou dar celeridade ao processo, garante que todos os solicitante de refúgio tenham direito a se inscrever no Cadastro de Pessoa Física, de obter uma Carteira de Trabalho e Previdência Social e de ter acesso à educação e à saúde.

$\S 2^{\circ} \mathrm{O}$ protocolo é prova suficiente da condição de solicitante de refúgio e servirá como identificação do seu titular, conferindo-lhe os direitos assegurados na Lei 9.474, de 1997, e os previstos na Constituição Federal, nas convenções internacionais atinentes ao tema do refúgio, bem como os mesmos direitos inerentes aos estrangeiros em situação regular em território nacional, até o trânsito em julgado do procedimento administrativo.

$\S 3^{\circ} \mathrm{O}$ protocolo dará ao solicitante de refúgio o direito de obter o CPF, bem como Carteira de Trabalho e Previdência Social, tendo este prazo de validade prorrogável sempre em correspondência com a validade do mencionado protocolo (CONARE, 2014, p.1).

$\mathrm{O}$ acesso facilitado a esses documentos possibilita que essas pessoas possam se inserir no mercado de trabalho, buscando formas de se manter economicamente, e assegura que usufruam dos mesmos direitos que os brasileiros.

Percebe-se, então, preocupação brasileira com a questão do refúgio através da politização e da juridicização do assunto. Isso mostra que em termos legislativos a questão foi burocratizada e existem órgãos responsáveis por estes indivíduos. Há, inclusive, a criação de normas para lidar especificamente com os imigrantes sírios, uma vez que se percebeu a gravidade do conflito que se iniciou no país em 2011. No entanto, é necessário analisar se o texto da lei está em conformidade com a realidade e se, na prática, essas pessoas estão de fato "inseridas" na sociedade brasileira. Essas questões serão analisadas nas seções que se seguem.

\subsection{O Discurso Internacional Brasileiro sobre o tema dos Refugiados Sírios}

O Brasil adota discurso internacional de valorização dos imigrantes e dos refugiados, permitindo sua entrada no país; assim como de condenação e de necessidade de responsabilização dos atores que propagam conflitos armados. Desde 2015 são mais visíveis em discursos brasileiros questões relacionadas à situação na Síria - seja em relação à guerra ou ao recebimento de refugiados. Os discursos relevantes são aqueles proferidos por representantes brasileiros Presidente e Ministros - em fóruns internacionais voltados para o tema - como a Conferência Internacional de Apoio à Síria e Região ou a Reunião de Alto Nível sobre Grandes Movimentos de Refugiados e Migrantes.

Há posicionamento mais firme em relação aos grupos denominados terroristas, que pode ser percebido no discurso brasileiro proferido na Reunião dos Ministros das Relações Exteriores dos BRICS (bloco formado pelo Brasil, Rússia, Índia, China e África do Sul), em setembro de 2015. Nele, discutiu-se sobre a existência de atividades terroristas perpetradas por organizações extremistas na Síria, as quais constituem ameaça direta não apenas aos países do Oriente Médio, como também à comunidade internacional. Além disso, os Ministros dos BRICS expressaram a convicção de que "uma abordagem abrangente é necessária para garantir um combate eficaz ao terrorismo" (MRE, 2015). 
Já em relação ao engajamento na questão dos refugiados, pode-se constatar uma evolução. Em outubro de 2015, o Secretário Nacional de Justiça e Presidente do CONARE, Beto Vasconcelos, o Alto Comissário Assistente para Proteção da Agência da ONU para Refugiados (ACNUR), Volker Türk, e a Representante Permanente do Brasil junto à ONU em Genebra, Embaixadora Regina Dunlop, assinaram documento de cooperação sobre o processo de concessão de vistos pelo Brasil a pessoas afetadas pelo conflito na Síria:

A cooperação prevê intercâmbio de informação, conhecimento e experiência, além de atividades de treinamento e capacitação, compartilhamento de material geral e específico, e também de técnicas de entrevista e de identificação de potenciais candidatos aos vistos emitidos com base na política humanitária do Governo brasileiro (MRE, 2016a).

Este acordo de cooperação entre o Brasil e o ACNUR é consequência direta da Resolução Normativa $n^{\circ} 20$, que prorrogou por mais dois anos a Resolução Normativa $n^{\circ} 17$, demonstrando que a preocupação com o acolhimento da população síria não teve sua importância diminuída e que o Brasil continuava comprometido a garantir que as pessoas tivesse acesso ao visto por razões humanitárias.

No que diz respeito à ajuda humanitária, o Brasil, na Conferência Internacional de Apoio à Síria e Região - que ocorreu em 4 de fevereiro de 2016, em Londres -, anunciou a doação de 1,3 milhões de dólares ao ACNUR com o propósito de aliviar o sofrimento de refugiados sírios. Além disso, reiterou a extensão em dois anos da política de visto humanitário, "abrindo seus braços para receber aqueles que fogem do conflito na Síria e da ameaça de terrorismo" (MRE, 2016b, tradução nossa).

Outro discurso relevante foi proferido pelo Presidente Michel Temer na Reunião de Alto Nível sobre Grandes Movimentos de Refugiados e Migrantes, de 19 de setembro de 2016, em que afirmou que:

(...) fluxos de refugiados são o resultado de guerras, de repressão, do extremismo violento - não são a sua origem. As preocupações legítimas dos governos com a segurança de seus cidadãos devem estar em consonância com os direitos inerentes a cada ser humano. Se abrirmos mão da defesa intransigente desses direitos, estaremos abrindo mão de nossa própria humanidade. Em nossa relação com o estrangeiro, com o outro, testamos a nossa fidelidade a esses valores, o nosso compromisso com a civilização (MRE, 2016c)

O reconhecimento de que os refugiados não são um problema é relevante para a percepção de que essas pessoas são de fato as maiores vítimas de conflitos e de violência em suas regiões. Em oposição ao discurso de que elas seriam responsáveis por causar instabilidades nos países de acolhida. Por esse motivo, manifestações internacionais do Brasil, trabalhando em conjunto com as Nações Unidas, demonstram o comprometimento do país com a acolhida de refugiados, buscando assegurar agilidade nos procedimentos de concessão desse status. Em grande parte dos pronunciamentos dos representantes brasileiros em fóruns internacionais que tratam especificamente da questão síria, reitera-se a importância da preocupação com os refugiados, enfatizando a ideia de que o Brasil estaria disposto a recebê-los. Dessa maneira, é possível vislumbrar que o discurso internacional proferido por representantes brasileiros está em conformidade com a legislação brasileira sobre a questão.

Após a análise da legislação e de discursos selecionados, pode-se concluir que o Brasil possui, em teoria, uma agenda positiva para o acolhimento dos refugiados sírios. Sendo assim, fazse necessário analisar como se dá a acolhida na prática dessas pessoas na sociedade brasileira, de 
modo a verificar se a realidade está em acordo com as promessas brasileiras presentes na lei e nos discursos.

\subsection{0 acolhimento dos Refugiados Sírios No Brasil}

Ao notar uma concordância entre a legislação brasileira e os discursos adotados internacionalmente sobre a questão do refúgio - principalmente aquele consentido aos refugiados sírios torna-se necessário observar se há conformidade, também, com a realidade que estes indivíduos enfrentam após sua acolhida no Brasil. A valorização dos imigrantes e refugiados - percebida na política de "portas abertas" e nas diversas resoluções criadas a fim de dar continuidade a uma recepção mais humanizada - não se traduz em uma acolhida facilitada e eficaz. Dessa forma, a acolhida dos refugiados é investigada através de meios jornalísticos, uma vez que se tratam de veículos onde a percepção destes indivíduos, das organizações que lidam com o assunto e, até mesmo, da sociedade podem ser retratadas. Por meio de entrevistas realizadas por estes noticiários, as próprias vozes dos refugiados sírios podem, inclusive, reproduzidas.

Assim, efetivamente, a percepção que estes têm ao se instalarem em território brasileiro mostra descontentamentos em relação à burocracia na emissão de documentos necessários, à dificuldade de reconhecimento de seus diplomas e à inexistência de políticas de integração adequadas. Essas barreiras acabam por obrigá-los a atuar em áreas completamente diferentes daquelas de sua formação.

Mesmo com a maior facilidade no deferimento das demandas efetuadas para o Brasil, este país tem recebido críticas relacionadas aos trâmites envolvidos no processo. Andrés Ramirez, representante do ACNUR, apesar de elogiar a iniciativa brasileira e a tentativa de manter a política de "portas abertas" para os refugiados sírios, critica a demora no processamento dos pedidos enfrentada pelo CONARE, o qual tem de lidar com um aumento crescente nas demandas (BARRUCHO, 2015). Isso já demonstra que os problemas enfrentados pelos refugiados se encontram, ainda, no processo de aceite das demandas, iniciando uma percepção já prejudicada do acolhimento no país.

Figura 1. Acolhida de refugiados no Brasil

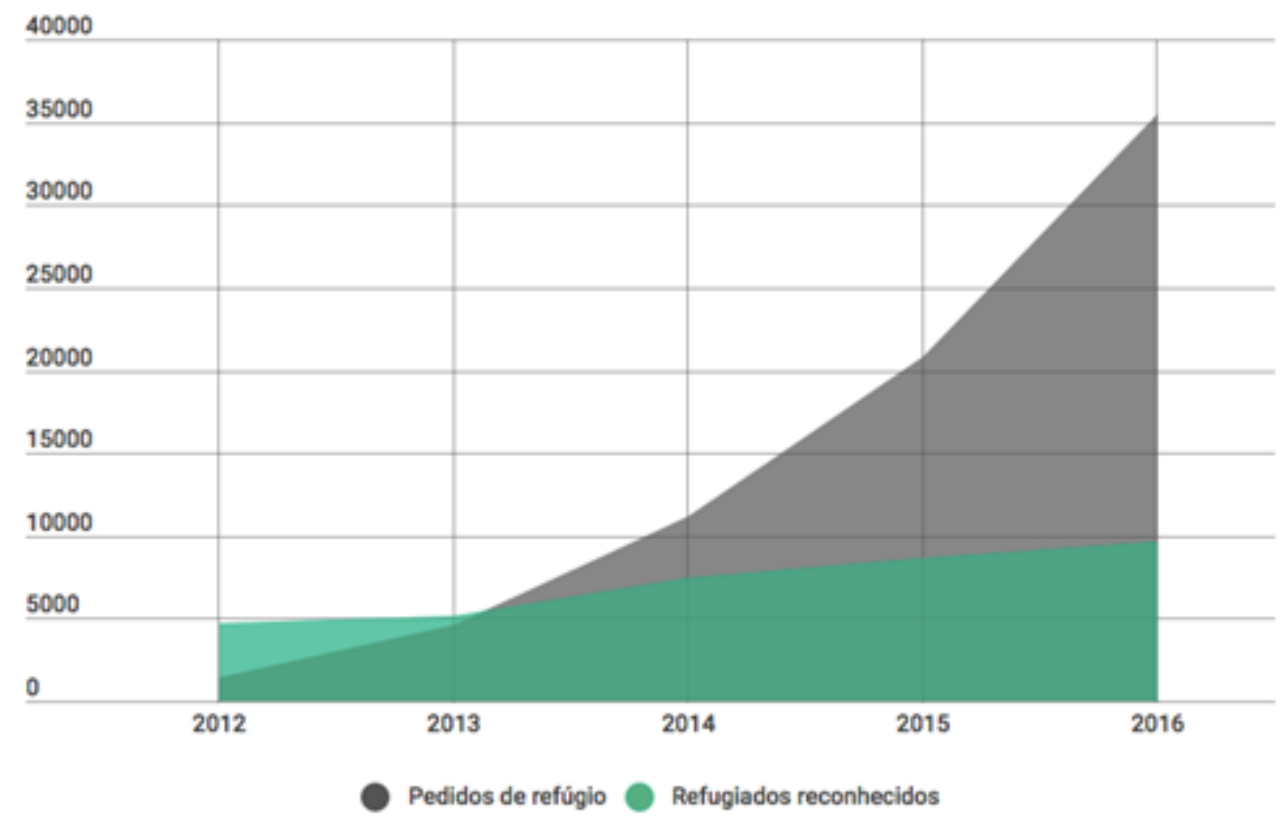

Fonte: ACNUR apud CONECTAS, 2017

A figura 1 acima ilustra a fala de Ramirez ao indicar um aumento exponencial das solicitações de refúgio que, em 2012, somavam cerca de 2 mil demandas e, em 2016, totalizava em pouco 
mais de 35 mil demandas. Em contrapartida o deferimento de tais demandas teve um leve aumento incomparável, porém, com o aumento nos pedidos. Em 2012, os deferimentos somavam pouco menos de 5 mil e, em 2016, esse número aumentou para aproximadamente 10 mil. Se em 2012, os aceites eram maiores que o dobro dos pedidos feitos no ano, em 2016, a situação se alterou drasticamente, com o aceite de menos de um terço das demandas feitas durante todo o ano.

Entre $1^{\circ}$ de janeiro e 31 de maio de 2017, a maior nação da América Latina recebeu 10.507 pedidos de refúgio, 199 a mais do que os 10.308 registrados durante todo o ano de 2016, o que, em apenas cinco meses, já representa uma alta de 1,93\%. Os dados são do Comitê Nacional para os Refugiados (Conare), órgão do Ministério da Justiça responsável por avaliar as solicitações (JORNAL DO BRASIL, 2017).

Dessa forma, uma modernização da estrutura do Comitê torna-se imprescindível para que a dinâmica dos processos - e o consequente aceite - seja feita de maneira ágil. A sugestão dada por Ramirez é a de considerar aumento efetivo no número de funcionários do órgão e uma melhoria na organização interna, para poder lidar com as demandas da melhor forma (BARRUCHO, 2015). Esta proposição ocorre porque o número de funcionários do órgão do Ministério da Justiça não é suficiente para processar todas as demandas, de modo que a demora gera um acúmulo de solicitação para serem analisadas pelos funcionários, sobrecarregados, além de que, para os refugiados, gera incertezas e os impossibilita de usufruir de outros direitos, como a reunião familiar, possível apenas para os refugiados já reconhecidos.

O Brasil tem 26 mil pedidos de refúgio pendentes de análise. E 13 pessoas para fazer o serviço. Além disso, o tempo de avaliação desses pedidos (em média um ano e meio) tende a aumentar, já que o governo decidiu não renovar o acordo com um braço da Organização das Nações Unidas que auxiliava a área com dez consultores.

Se hoje parassem de chegar pedidos de refúgio no Brasil, os 13 encarregados teriam de analisar mais de 2 mil casos até o fim do ano para zerar o estoque (VASCONCELLOS, 2017, s/p).

Outro desafio apontado pelo representante do ACNUR é o de integração à sociedade brasileira, tanto social quanto econômica e culturalmente. Trata-se de dificuldade, visto que, após a chegada dos solicitantes de refúgio em território brasileiro, todo o procedimento de regularização da estadia no país se insere nos trâmites do CONARE e, enquanto essas pessoas aguardam a regulamentação do seu status, não existe, por parte do governo, políticas de integração adequadas que as envolvam.

Somado a isso, há o fato de que muitos deles, mesmo possuindo diplomas acadêmicos e profissionais na Síria, encontram dificuldades em reconhecê-los no Brasil, o que os obriga a buscar outras áreas de atuação, já que necessitam da renda para se manterem. Muitos deles, inclusive, são os primeiros familiares a chegarem ao país e a busca por uma renda se torna essencial para que consigam reunir dinheiro suficiente para realizar a reunião familiar.

O excesso de burocracia nas universidades resultou em um vagaroso processo de revalidação/reconhecimento, num acesso disperso à informação por parte dos requerentes e, por consequência, numa situação de insegurança jurídica quanto à validade de diplomas, com prejuízos potenciais à sociedade, ao Estado, à ciência e às próprias instituições de ensino superior.

As evidências desses obstáculos tornaram-se bastante concretas nos relatos de imigrantes, como identificou o estudo da DAPP [Diretoria de Análise de Políticas Públicas] "Análise e Avaliação do Desenvolvimento Institucional da Política de Imigração no Brasil para o Século XXI", a partir de grupos focais com imigrantes, refugiados e portadores de vistos humanitários no Brasil. A necessidade de 
validação do diploma e reconhecimento de titulação deixa de ser atendida pelos imigrantes devido à demora dos conselhos universitários para se reunir e deliberar sobre os pedidos, devido ao trâmite burocrático longo e custoso, dentre outros motivos. Mesmo com o diploma validado em mãos, muitas vezes os imigrantes, com permissão temporária ou permanente de trabalho, precisam que conselhos profissionais autorizem o exercício da profissão, como todo profissional, mais um passo no longo processo para exercício da formação adquirida no exterior (FERNANDES, et al, 2017, s/p).

Quando um refugiado sírio chega ao Brasil, sem conhecer a realidade local e sem falar a língua, sustentar-se é um desafio. Ao deixarem suas casas, os sírios acabam deixando também boa parte de seus parentes, dos documentos - incluindo diplomas e outros comprobatórios de formação - e dos empregos. Para poder transpor tamanha distância como a viagem da Síria ao Brasil, é preciso ter certa quantia de dinheiro que os permita arcar com o deslocamento. Dessa forma, grande parte dos solicitantes de refúgio que chegam ao Brasil são aqueles que possuíam certa estabilidade financeira na Síria: muitos atuavam como engenheiros, médicos ou administradores. Chegar ao Brasil, e continuar atuando "dentro dessas atividades é quase impossível, seja por burocracia, seja por dificuldades com o idioma, seja pelo tempo que essa inserção demanda - e boa parte deles simplesmente não tem como esperar" (ALMEIDA, 2015).

Assim, inserir-se na culinária acaba sendo a forma mais rápida de acesso a uma renda e de iniciar, de fato, uma nova vida no Brasil, já que, de acordo com o presidente do Instituto Adus, ONG de acolhimento a refugiados com atuação desde 2010, Marcelo Haydu, grande parte dos refugiados têm alto nível educacional e dominam vários idiomas, mas, possuem dificuldade em validar o diploma e se inserir em suas áreas de formação (ALMEIDA, 2015).

Além de atuarem na acolhida desses refugiados e na criação de políticas de integração, algumas ONGs ou entidades da Sociedade Civil organizada, como a Cáritas e os centros de cultura árabe, como a Mesquita Brasil, encarregam-se de oferecer apoio financeiro a esses indivíduos, dada a lacuna por parte do governo. Esse descaso é criticado por Nasser Fares, presidente da Sociedade Beneficente Muçulmana, que afirma ser comum deparar-se com indivíduos que chegam ao país apenas com uma muda de roupas e dependem do auxílio de ONGs e entidades, uma vez que o governo não fornece condições necessárias para o estabelecimento no país (ALMEIDA, 2015).

Além disso, após uma longa espera para receber o aceite à demanda, ainda há problemas no momento da acolhida, visto que refugiados e imigrantes são atendidos pela Polícia Federal no aeroporto. Trata-se de órgão que não recebe capacitação e preparo para esse tipo de atendimento, o que faz com que ele não seja executado da forma humanitária que a situação demanda. Isso é verificado quando refugiados afirmam sentirem medo ou receio de irem até a Polícia Federal ou serem atendidos por seus funcionários - o que se torna outro obstáculo para que o processo caminhe normalmente. Há ainda quem acredite que esse tratamento dado pela Polícia Federal é uma forma de securitização da questão da imigração. Emerson Andena, professora da Unicamp e especialista em legislação imigratória, afirma que o acolhimento feito por este órgão pode criar interpretações de que a imigração é, antes de tudo, uma questão de segurança nacional (ALMEIDA, 2015).

Assim, é possível perceber discrepâncias entre a legislação brasileira e o que, de fato, está envolvido no processo de acolhimento e de regularização de refugiados sírios no Brasil. Apesar de propagar uma política de "portas abertas" e de realizar movimentação para que se crie uma legislação que facilite a entrada dessas pessoas ao país, os passos posteriores a esta entrada mostram a grave situação. O Brasil não está preparado para o que surge após a aceitação e a acolhida de indivíduos que solicitam refúgio - não possui políticas de integração adequadas, não fornece auxílio financeiro ou de moradia, não cria condições para que as pessoas consigam atuar em suas áreas de especialização, não auxiliam no aprendizado da língua local, entre outros. Isso faz com que esses indivíduos, ao entrarem no país, não possuam assistência e acabem tendo de resolver 
estes problemas sem auxílio algum do Estado, dependendo da assistência de entidades humanitárias - se existentes.

\section{A FRANÇA FRENTE AOS REFUGIADOS SÍRIOS}

A França é um dos países da União Europeia mais buscados pelos solicitantes de refúgios advindos da Síria. Sendo assim, é um dos Estados que mais se empenha em encontrar uma solução consentida e uniforme no âmbito da União Europeia para solucionar essa questão.

\subsection{A legislação europeia de refúgio}

A França, por fazer parte da União Europeia, sendo um de seus membros fundadores, possui legislação comum de asilo regida pela Convenção de Dublin de 1990. Referida Convenção, assinada quando ainda se tratava de Comunidades Europeias, estabelecia os critérios para o estabelecimento de único Estado responsável pela análise da solicitação de refúgio. Essa Convenção buscava evitar que vários países analisem a solicitação de um mesmo indivíduo, de modo a gerar economia processual e diminuição da burocracia. A regra geral era a de que a análise deveria ser realizada pelo Estado que permitiu que o requerente adentrasse ao espaço comum, denominado área Schengen, ou por ser o primeiro Estado signatário pelo qual transitou o requerente. É esse país, pois, que deveria analisar a solicitação da proteção internacional

Além desses termos, a Convenção de Dublin estabeleceu: (i) a ideia de um "país" seguro, sendo aquele por onde o solicitante passou em seu caminho à área comum e posterior ao qual não é possível solicitar asilo; (ii) a necessidade de que a solicitação seja manifestamente fundada; (iii) sanções contra transportadoras que realizem tráfico de pessoas, por meio da facilitação dos chamados caminhos de refúgio; e (iv) a solidariedade entre os países europeus, de modo que a recusa de um país em conceder o asilo será aplicada a todos os demais países do bloco.

Em 2003, a Convenção de Dublin foi substituída pelo Regulamento Dublin II, que tinha como objetivo identificar mais rapidamente o Estado Membro responsável pelo exame da solicitação de refúgio, de modo a evitar o chamado abuso do procedimento de refúgio. A partir de 2009 o Parlamento Europeu buscou revisar esse mecanismo, na medida em que o sistema em vigor não era capaz de distribuir pedidos de refúgio entre os Estados-Membros, dando início à aprovação do chamado Regulamento Dublin III em 2013. De acordo com as Nações Unidas, teve início em 2015 a maior crise de mobilidade humana desde a Segunda Guerra Mundial. Dado que Dublin III determina que a regra geral é a de que o primeiro país de entrada deve se encarregar da análise e da decisão sobre a solicitação de refúgio, Estados de fronteira da União, como Grécia e Itália, ficaram sobrecarregados, não conseguindo acolher todos os solicitantes (PARLAMENTO EUROPEU, 2017). .

No ano de 2016, a Comissão Europeia propôs mecanismo que pudesse assegurar igualdade na análise dessas demandas, de maneira que os Estados Membros partilhassem essa responsabilidade proporcionalmente com base no tamanho de sua economia e de sua população. Há concordância dos eurodeputados de que todos os Estados Membros devem assumir a sua quotaparte de responsabilidade (PARLAMENTO EUROPEU, 2017), porém Estados como a Polônia e a Hungria se recusam a exercer o princípio de solidariedade e receber solicitantes de refúgio.

Para além do sistema europeu e de acordo com os instrumentos internacionais aplicáveis, o reconhecimento de um título de proteção na França pressupõe que o pedido possa satisfazer as razões e as condições de diversos instrumentos. Como base para que uma pessoa possa ser reconhecida como refugiado na França, cinco condições devem ser respeitadas: I. temor atual: a razão que faz com que a pessoa solicite proteção devem estar presentes na data de apreciação da demanda; II. temores pessoais: o medo deve ser individualizado; III. temores graves: análise da gravidade e da frequência das violações de direitos humanos sofridas; IV. temores que não 
encontram proteção efetiva e permanente: a proteção internacional é sempre complementar, si o Estado que deveria proteger a pessoa não tem a capacidade ou a vontade de fazê-lo; V. temor na totalidade do território de um Estado: se o Estado for territorialmente grande e a pessoa puder se proteger em outra região.

\subsection{O Discurso Internacional Francês sobre o tema dos Refugiados Sírios}

A França possui discurso mais cauteloso quando se trata da questão dos refugiados. Apesar de aparentemente aberta à entrada de grupos mais vulneráveis, é possível perceber em seus discursos preocupação com a chamada segurança nacional - o que faz com que a análise das demandas tenha necessidade de avaliação mais minuciosa - e uma cobrança de que outros países da União Europeia se engajem na causa do recebimento dos refugiados - de modo que o "problema", como muitas vezes é tratado, seja igualmente dividido entre os países da região.

A posição da França se tornou ainda mais cautelosa a partir do momento em que o país se tornou alvo direto de ataques terroristas de grupos envolvidos na Guerra da Síria, como o autodenominado Estado Islâmico. Em razão desse envolvimento francês no conflito - admitido, inclusive, pelo ex-presidente francês François Hollande - o país tem sofrido ataques como forma de retaliação. Como consequência, percebe-se endurecimento nos discursos presidenciais e de ministros no que diz respeito à participação francesa na Síria e, também, no engajamento francês no acolhimento de refugiados sírios.

Em discurso proferido no dia 16 de novembro de 2015 - três dias após os ataques que aconteceram em Paris - o ex-presidente Hollande afirma que "a França está em guerra" (FRANCE DIPLOMATIE, 2015a, tradução nossa) e que os ataques foram destinados à França, especificamente, por ser um país de liberdade e que deu início aos direitos humanos (FRANCE DIPLOMATIE, 2015a). Assim, o presidente afirma que, nesta guerra, a França responderá com mais força e, eventualmente, vencerá (FRANCE DIPLOMATIE, 2015b).

Uma das medidas que o presidente adotou logo após os atentados do dia 13 de novembro de 2015 foi o fechamento das fronteiras para "assegurar que ninguém entre e cometa qualquer ato como aquele do dia 13 de novembro" (LE FIGARO, 2015, tradução nossa). O presidente afirmou que, por conta desses atentados, iria reforçar as operações na Síria, de modo que mais ataques aéreos às bases do Estado Islâmico foram ordenados (FRANCE DIPLOMATIE, 2015a). No entanto, ataques aéreos apresentam lado controverso em termos de violações de direitos humanos, na medida em que difícil distinguem entre civis e combatentes

Além disso, Hollande, ao retomar o artigo 42 do Tratado da União Europeia, expressa que "todos os Estados-Membros devem ter a obrigação de fornecer ajuda e assistência, porque, neste caso, o inimigo não é somente inimigo da França, é inimigo da Europa" (FRANCE DIPLOMATIE, 2015a, tradução nossa). Dessa maneira, o então Presidente traz a questão dos refugiados para a atenção dos demais países europeus, como forma de mostrar-lhes que têm, também, obrigação de receber aqueles elegíveis à condição de refugiado, mas que devem recusar aqueles que acreditam não ser. Para que isso ocorra, é necessário atenção às fronteiras externas. Ele ainda atestou haver necessidade de melhorar o processo de expulsão de pessoas que representam possível ameaça à segurança do país (FRANCE DIPLOMATIE, 2015a).

O Ministro Laurent Fabius, também trata do assunto e afirma que "a continuação do conflito e a deterioração das condições de vida na Síria, bem como nos países vizinhos, significam que o número de aplicações deve aumentar, o que pode levar a tempos de processamento mais longos" (FRANCE DIPLOMATIE, 2016, tradução nossa). Adiciona também, que a recusa não é efetuada de forma arbitrária e que os pedidos são examinados e baseados em critérios internacionalmente reconhecidos.

Em 2017, o Presidente francês Emmanuel Macron apresentou ao Conselho de Ministros um texto de lei que visa acelerar a decisão sobre os processos de solicitação de refúgio na França, 
reduzindo de treze para seis meses o tempo de espera da resposta final. A nova lei de migração, aprovada em abril de 2018 entrou em vigor no início de 2019. Desde 2015 o fluxo de migrantes para a Europa caiu consideravelmente, retornando a níveis anteriores à chamada "crise de migração". Apesar do uso do termo crise para os fluxos migratórios, é inegável a existência de uma crise política no âmbito da União Europeia, em que país do leste e do sul da Europa - os Visegrad ${ }^{3}$, a Áustria e a Itália - se antagonizam aos países da Europa ocidental - Alemanha, França e Espanha - no tocante à aceitação e à repartição de solicitantes de refúgio. Enquanto aqueles se recusam a receber quotas de imigrantes, denunciando "sofrerem" com a grande quantidade de solicitações, esses reforçam a necessidade de valorização do princípio da solidariedade europeia e que todos deveriam ter as mesmas responsabilidades.

Figura 2. Chegadas irregulares mensais na Europa (2015-2018)

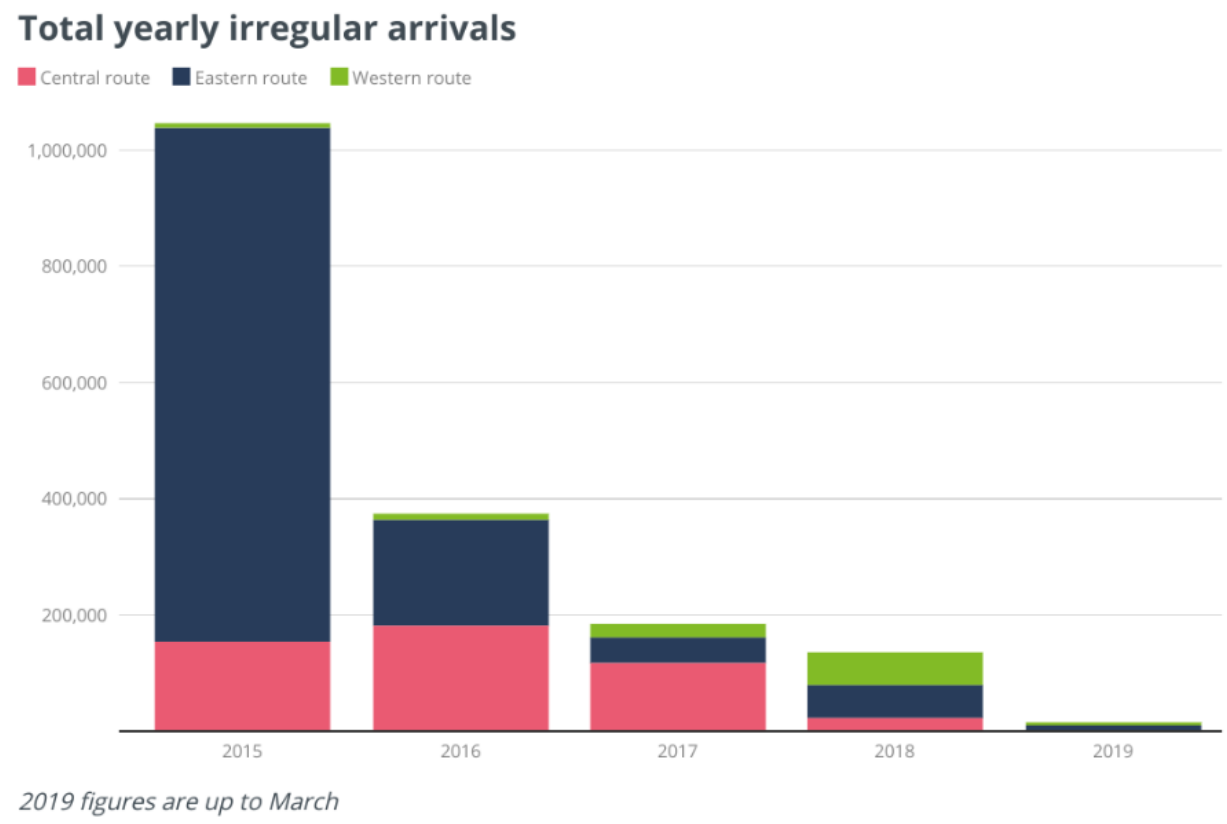

Fonte: Conselho da Europa (2018).

Considerando que a França faz parte de um bloco político-econômico em que as decisões devem ser sopesadas por diferentes atores e que a proximidade geográfica faz com que o país receba mais solicitações de refúgio que o Brasil, é possível compreender a origem do discurso francês e o porquê de ele ser mais cauteloso que o do Brasil. No entanto, tratar a imigração como questão de segurança, fortalecendo as fronteiras e proibindo a entrada de pessoas pelas vias regulares não é uma solução para se tratar a situação.

\subsection{A acolhida dos refugiados sírios na França}

Não há, no âmbito da União Europeia uma política comum de integração e de acolhida de refugiados. Dessa forma, a ajuda e o direito socioeconômico garantidos aos refugiados e aos solicitantes de refúgio variam dependendo do Estado em que a demanda foi realizada. Segundo o Escritório de Proteção a Refugiados e a Pessoas Apátridas (da sigla em francês OFPRA, Office Français de Protection des Réfugiés et Apatrides), em 2018 a França recebeu 122.743 solicitações de refúgio, tendo sido reconhecidas $27 \%$ das demandas

O processo de solicitação de refúgio na França envolve três instâncias e dura cerca de treze meses. Primeiramente, o indivíduo deve se inscrever em uma plataforma do governo presente

\footnotetext{
${ }^{3}$ Grupo informal formado pela Hungria, pela República Tcheca, pela Eslováquia e pela Polônia.
} 
em algum posto de migração em sua cidade. Após o registro, que varia de dez semanas a três meses, o imigrante receberá duas visitas do Escritório Francês para a Imigração e Integração. Após a segunda visita será decidido quanto à concessão ou não do status de solicitante de asilo ao migrante (OFPRA, s/d).

Desde o momento da inscrição de solicitação de refúgio o imigrante já pode se hospedar em um centro de acolhida para solicitantes de refúgio. Teoricamente essa hospedagem estará disponível durante todo o tempo de análise da demanda. Na prática, porém, a quantidade de leitos disponíveis para hospedagem é inferior às solicitações. Em 2017, apenas 47\% dos solicitantes de refúgio foram de fato hospedados nos centros públicos (FÓRUM RÉFUGIÉS, 2018). Caso seja averiguado que o imigrante disponha de recursos financeiros, é possível que lhe seja demandada uma caução que não deve ultrapassar 150 euros. Caso o refúgio seja concedido, o indivíduo poderá ficar na acomodação até seis meses depois do resultado, no entanto, em caso negativo, precisará deixá-lo em até um mês (SERVICE PUBLIC, 2017).

Como solicitante de refúgio, o imigrante não terá autorização para trabalhar em um período de nove meses, por isso é possível que lhe seja assegurada ajuda de custo, que irá variar de acordo com a sua condição financeira (SERVICE PUBLIC, 2017). A impossibilidade de que o solicitante trabalhe enquanto aguarda a decisão sobre sua situação na França dificulta a sua independência e o seu relacionamento com pessoas diferentes de sua nacionalidade. $O$ conhecimento da língua francesa se apresenta como um grande desafio para a integração desses solicitantes de refúgio e refugiados à sociedade francesa. Por esse motivo, o agrupamento dessas pessoas nos chamados guetos, à margem da sociedade francesa e longe dos grandes centros, demonstra a falha no processo de integração. Estar em um ambiente de trabalho permite que o indivíduo estabeleça uma rotina e possa interagir com outras pessoas, de modo que passe a se sentir parte também da sociedade de acolhida.

Figura 3. Solicitação de Refúgio na França

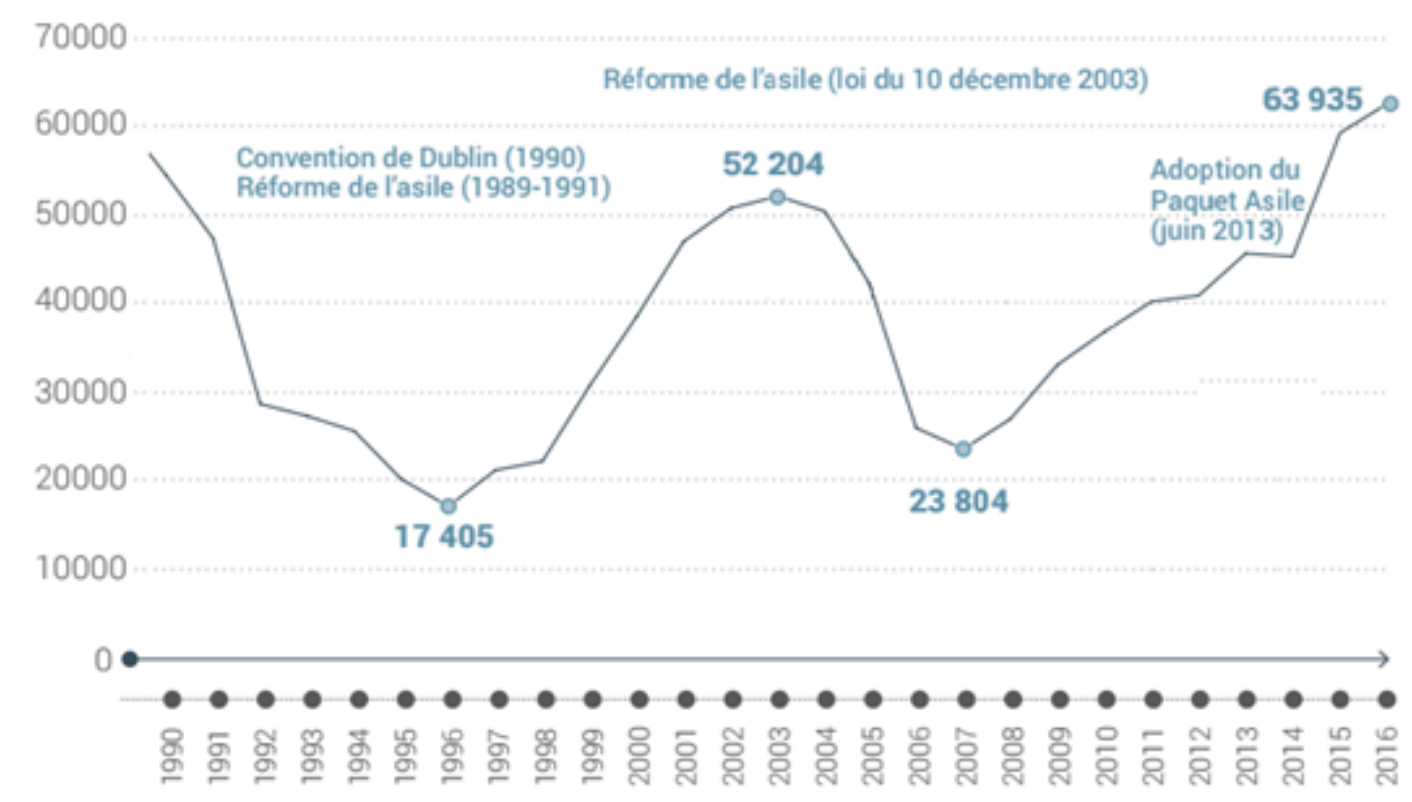

Fonte: OFPRA, 2016, p.109

Como é possível visualizar na figura 3, desde 2007 há aumento crescente em termos de solicitação de refúgio na França, o que faz ressurgir o debate sobre qual o modelo de acolhida o país deve implementar. 
O termo integração compõe o vocabulário social e sobretudo assume o caráter de uma política nacional a partir dos anos 1980 na França. A tradição política de integração dos imigrantes em solo francês se constituiu historicamente a partir da perspectiva assimilacionista (GEBRIM, 2013, p. 8).

Nas últimas eleições de 2016, em que o segundo turno foi disputado entre Emmanuel Macron, do En Marche, e Marine Le Pen, do Front National, o debate sobre qual a forma adequada de se acolher os refugiados voltou à cena. Historicamente a França é reconhecida como um país que busca assimilar os imigrantes, em vez de buscar uma posição multicultural.

A assimilação e o multiculturalismo estão nos dois polos do espectro de integração, levados em sentido genérico. Na França, uma nação centralizada que sofreu imigração precoce, a assimilação foi por muito tempo evidente. (...) A assimilação foi repudiada por todo o espectro político, com exceção da Frente Nacional. (...) A França, desde 2004, optou (...) por um modelo multicultural. O multiculturalismo considera uma nação como um espaço geopolítico em que comunidades culturais separadas convivem pacificamente com o mesmo status legal e social (TRIBALAT, 2015, s/p, tradução nossa).

Por outro lado, há autores que questionam a própria necessidade de integração do imigrante na cultura francesa:

As recentes evoluções impuseram um uso obrigatório da noção de integração. Embora isso possa ser lido como um longo processo de instalação "bem-sucedida" do estrangeiro na sociedade francesa (ou mesmo como culminação desse processo), tornou-se um pré-requisito para o migrante. A possibilidade de sua presença duradoura agora está condicionada pela sua "integração republicana" na sociedade francesa ", apreciada em particular em vista de seu compromisso pessoal de respeitar os princípios que regem a República Francesa, o respeito efetivo desses princípios e seu conhecimento suficiente da língua francesa". Em caso de incumprimento do contrato que lhe foi imposto, o estrangeiro não pode renovar a sua autorização de residência temporária ou não receber o seu cartão de residência (BLUM LE COAT; EBERHARD, 2014, tradução nossa).

Um dos problemas relacionados à integração dos refugiados sírios na sociedade francesa ocorre em razão da burocracia envolvida na análise da demanda realizada por este indivíduo. A demora na avaliação e posterior decisão da concessão do status de refugiado para determinados indivíduos os mantém à margem da sociedade. Isso acontece porque, ao permanecerem no aguardo da decisão, essas pessoas são impossibilitadas de buscarem uma forma de subsistência - já que não estão devidamente regularizadas no país. Por esse motivo, ficam isoladas da vida em sociedade e envolvidas na burocracia francesa, ao mesmo tempo em que necessitam da regularização de forma rápida, para que consigam inserir-se no mercado de trabalho e possam iniciar uma nova vida com garantias de salário, educação e saúde.

\section{CONCLUSÃO}

Neste artigo buscamos analisar dois modelos distintos de acolhida, de reconhecimento e de integração de solicitantes de refúgio e de refugiados: o caso brasileiro e o caso francês. Para ambos, as análises se basearam no estudo da legislação vigente sobre a concessão do status de refugiado, dos discursos proferidos em fóruns internacionais sobre a temática e do tratamento dado a essas pessoas uma vez que estão no país de acolhida. 
Na análise da situação brasileira, foi possível perceber que tanto a legislação em vigor, quantos os discursos proferidos possuem visão humanista de proteção e de acolhimento da população que está fugindo da grave e generalizada violação de direitos humanos perpetradas na Síria desde o início dos conflitos em 2011. No entanto, a realidade demonstra que há ainda muito a ser feito. Dificuldades burocráticas e linguísticas são os principais entraves na vida desses refugiados e solicitantes de refúgio no Brasil. Na situação francesa, a legislação da União Europeia aparentemente diminuiria os casos de solicitação de refúgio na França, na medida em que determina que os primeiros países da zona Schengen seriam os responsáveis por processar as demandas. No entanto, na prática isso não ocorre, uma vez que as pessoas que entram na União Europeia buscam normalmente os mesmos destinos, como a Alemanha, a França e a Inglaterra. A tentativa de dividir as responsabilidades sobre essas pessoas por meio do estabelecimento de quotas tem gerado atritos entre os Estados-membros, desgastando a união do bloco. Os discursos franceses, mais cautelosos sobre a questão, se refletem nas políticas de acolhimento, em que se debate a opção pela integração, pelo multiculturalismo ou pela assimilação.

Apesar das diferenças entre ambos os modelos no tocante à legislação que regula essa solicitação percebe-se que há uma falha no tocante ao acolhimento dessas pessoas. No caso brasileiro, a legislação permite que desde que o imigrante preencha o formulário de solicitação de refúgio na Polícia Federal, já tenha direito ao CPF e à carteira de trabalho, permitindo-lhe o acesso aos sistemas de saúde e à educação. Em contrapartida, na realidade francesa é necessário que se passe um período que pode chegar a três meses para que esse imigrante seja considerado um solicitante de asilo. Nesse período é possível que ele tenha acesso a acomodações do governo, o que não ocorre no caso brasileiro. Outra diferença está presente na exteriorização da política de refúgio nos discursos. No caso brasileiro há afirmação de respeito aos direitos humanos e de uma política voltada para o acolhimento, enquanto no caso francês, apesar da ênfase na proteção dos direitos humanos, a questão é tratada com mais cautela.

As promessas internacionais brasileiras, portanto, não correspondem com a realidade dos refugiados sírios neste país. Do outro lado, a França, apesar de ter um número relevante de solicitações se comparado ao Brasil, mantém internacionalmente um discurso mais cauteloso, que está em conformidade com o que se passa internamente: cautela e burocracia envolvida na análise das demandas. Conclui-se, pois, não haver entre os dois modelos analisados, um que seja referência no trato da questão, posto que, apesar de ambos possuírem pontos positivos - como a garantia de documentos que permitem o acesso à saúde e ao trabalho no caso brasileiro e a possibilidade de permanecer em alojamentos governamentais no caso francês -, há ainda muito a ser feito no tocante a uma acolhida mais humanitária de solicitantes de refúgio e de refugiados sírios.

\section{REFERÊNCIAS}

ACNUR. Um recomeço para os refugiados Sírios no Brasil. Disponível em: <http://www.acnur.org/portugues/noticias/noticia/um-recomeco-para-os-refugiados-sirios-nobrasil/>. Acesso em: 15 out. 2017.

ALMEIDA, Camila. Para refugiados sírios no Brasil, a comida é um recomeço. Exame. 14 agosto 2015. Disponível em: <https://exame.abril.com.br/pme/para-refugiados-sirios-a-comida-eum-recomeco/>. Acesso em: 30 out. 2017.

BARRUCHO, Luís Guilherme; COSTA, Camilla. Brasil acolhe mais sírios que países na rota europeia de refugiados. BBC Brasil. Londres e São Paulo, 9 setembro 2015. Disponível em: <http://www.bbc.com/portuguese/noticias/2015/09/150904_brasil_refugiados_sirios_comparacao _internacional_lgb>. Acesso em: 25 out. 2017 
BLUM LE COAT, Jean-Yves; EBERHARD, Mireille. Législations et politiques migratoires en France. In: Les immigrés en France. 2014.

BRASIL. Lei 9.474/1997: Define mecanismos para a implementação do Estatuto dos Refugiados de 1951, e determina outras providências. 1997. Disponível em <http://www.planalto.gov.br/ccivil_03/leis/19474.htm>. Acesso em: 13 mai. 2019.

BRASIL. Lei 13.445/2017: Institui a Lei de Migrações. 2017. Disponível em: <http://www.planalto.gov.br/ccivil_03/_ato2015-2018/2017/lei/113445.htm>. Acesso: 13 mai. 2019.

CAMINHOS DO REFÚGIO. Cartagena +30 e a adoção da Declaração do Brasil sobre Refugiados, Apátridas e deslocados. 2014. Disponível em:

<https://caminhosdorefugio.com.br/tag/declaracao-de-cartagena/>. Acesso em: 13 mai. 2019.

CONARE. Resolução Normativa CONARE No 17 de 20/09/2013: Dispõe sobre a concessão de visto apropriado, em conformidade com a Lei ${ }^{\circ} 6.815$, de

19 de agosto de 1980, e do Decreto 86.715, de 10 de dezembro de 1981, a indivíduos forçosamente deslocados por conta do conflito armado na República Árabe Síria. 2013. Publicado no DO em 24 set 2013. Disponível em: <https://www.conjur.com.br/dl/resolucao-siriarefugiados.pdf>. Acesso em: 12 mai. 2019.

CONARE. Resolução Normativa CONARE Nº 18 de 30/04/2014: Estabelece os procedimentos aplicáveis ao pedido e tramitação da solicitação refúgio e dá outras Providências. 2014. Disponível em: < http://www.justica.gov.br/seusdireitos/migracoes/refugio/anexos/resolucao-18-dou-pdf.pdf>. Acesso em: 13 mai. 2019.

CONECTAS. A vida deixada para trás. 2017. Disponível em: < https://www.conectas.org/noticias/a-vida-deixada-para-tras>. Acesso em: 13 mai. 2019.

CONSELHO DA UNIÃO EUROPEIA. Infografia - Migration flows: Eastern, Central, and Western Mediterranean routes. UE. 2019. Disponível em:

<https://www.consilium.europa.eu/pt/infographics/eastern-and-central-mediterranean-routes-092017/>. Acesso em: 13 mai. 2019.

DW. Zeitgeist: A convenção de Genebra sobre refugiados. 2017. Disponível em: <https://www.dw.com/pt-br/zeitgeist-a-conven\%C3\%A7\%C3\%A3o-de-genebra-sobrerefugiados/a-37338014>. Acesso em: 13 mai. 2019.

FERNANDES, Janaina de Mendonça; SPOHR, Alexandre; SANCHES, Danielle. Revalidação e reconhecimento de diplomas no Brasil: uma via-crúcis perto do fim? FGV DAPP. Disponível em: $<$ http://dapp.fgv.br/revalidacao-e-reconhecimento-de-diplomas-no-brasil-uma-via-crucis-pertofim/>. Acesso em: 13 mai. 2019.

FÓRUM RÉFUGIÉS. Hébergement des demandeurs d'asile: quelles perspectives en 2019? 2018. Disponível em: <http://www.forumrefugies.org/s-informer/actualites/hebergement-desdemandeurs-d-asile-quelles-perspectives-en-2019>. Acesso em: 13 mai. 2019.

FRANCE DIPLOMATIE. Speech by the President of the Republic before a joint session of Parliament (Versailles, November 16, 2015), 2015a. Disponível em: 
<http://www.diplomatie.gouv.fr/en/french-foreign-policy/defence-security/parisattacks-paristerror-attacks-november-2015/article/speech-by-the-president-of-the-republic-before-a-jointsession-of-parliament>. Acesso em: 01 jun. 2016.

FRANCE DIPLOMATIE. Syrie - Prolongation de l'engagement des forces aériennes françaises en Syrie (25 novembre 2015), 2015b. Disponível em: <http://www.diplomatie.gouv.fr/fr/anciensministres/laurent-fabius-2012-2016/interventions-a-1-assemblee-nationale-et-ausenat/article/syrie-prolongation-de-l-engagement-des-forces-aeriennes-francaises-en-syrie-25> . Acesso em: 27 mai. 2016.

FRANCE DIPLOMATIE. Déclarations officielles de politique étrangère du 12 janvier 2016. Disponível em: <http://basedoc.diplomatie.gouv.fr/vues/Kiosque/FranceDiplomatie/kiosque.php?fichier=bafr201 6-01-12.html\#Chapitre5>. Acesso em: 15 nov. 2017.

GEBRIM, Ana. Entre assimilação e coação: uma noção de integração sob a perspectiva das políticas de imigração francesas. Disponível em: <http://seer.fclar.unesp.br/cadernos/article/view/7362>. Acesso em: 17 nov. 2017.

JORNAL DO BRASIL. Em 5 meses, Brasil tem mais pedidos de refúgio que em 2016. Disponível em: < http://www.jb.com.br/pais/noticias/2017/06/19/em-5-meses-brasil-tem-maispedidos-de-refugio-que-em-2016/> . Acesso em 30 nov. 2017.

LE FIGARO. François Hollande décrète l'état d'urgence. 2015 Disponível em: <http://www.lefigaro.fr/actualite-france/2015/11/14/01016-20151114ARTFIG00005-francoishollande-annonce-la-fermeture-des-frontieres.php>. Acesso em: 4 jun. 2016.

MINISTÉRIO DAS RELAÇÕES EXTERIORES (Comp.). Reunião dos Ministros das Relações Exteriores dos BRICS. Disponível em: <http://www.itamaraty.gov.br/pt-BR/notas-aimprensa/11939-reuniao-dos-ministros-das-relacoes-exteriores-dos-brics-nova-york-29-desetembro-de-2015>. Acesso em: 15 nov. 2017.

MINISTÉRIO DAS RELAÇÕES EXTERIORES (Comp.). Parceria entre Brasil e ACNUR para concessão de vistos a pessoas afetadas pelo conflito na Síria. 2016a. Disponível em:

<http://www.itamaraty.gov.br/pt-BR/notas-a-imprensa/12016-parceria-entre-brasil-e-acnur-paraconcessao-de-vistos-a-pessoas-afetadas-pelo-conflito-na-siria>. Acesso em: 14 nov. 2017.

MINISTÉRIO DAS RELAÇÕES EXTERIORES (Comp.). Discurso do Ministro Mauro Vieira por ocasião da Conferência Internacional de Apoio à Síria e Região. 2016b. Disponível em: $<$ http://www.itamaraty.gov.br/pt-BR/discursos-artigos-e-entrevistas-categoria/ministro-dasrelacoes-exteriores-discursos/13095-discurso-do-ministro-mauro-vieira-por-ocasiao-daconferencia-internacional-de-apoio-a-siria-e-regiao-londres-4-de-fevereiro-de-2016-ingles>. Acesso em: 14 nov. 2017.

MINISTÉRIO DAS RELAÇÕES EXTERIORES (Comp.). Discurso do Senhor Presidente da República, Michel Temer, durante Reunião Alto Nível sobre Grandes Movimentos de Refugiados e Migrantes. 2016c. Disponível em: <http://www.itamaraty.gov.br/pt-BR/discursos-artigos-eentrevistas-categoria/presidente-da-republica-federativa-do-brasil-discursos/14755-discurso-dosenhor-presidente-da-republica-michel-temer-durante-reuniao-alto-nivel-sobre-grandes- 
movimentos-de-refugiados-e-migrantes-nova-york-19-de-setembro-de-2016>. Acesso em: 14 nov. 2017.

OFFICE FRANÇAIS DE PROTECTION DES RÉFUGIÉS ET APATRIDES (OFPRA). La procédure de demande d'asile. S/d. Disponível em: <https://ofpra.gouv.fr/fr/asile/la-procedurede-demande-d-asile/demander-l-asile-en-france>. Acesso em: 13 mai. 2019.

OFFICE FRANÇAIS DE PROTECTION DES RÉFUGIÉS ET APATRIDES (OFPRA). Rapport d'activité 2016. Disponível em:

<https://ofpra.gouv.fr/sites/default/files/atoms/files/rapport_dactivite_ofpra_2016_1.pdf>.Acesso em 30 nov. 2017.

PARLAMENTO EUROPEU. A reforma do sistema europeu comum de asilo. Disponível em: Mhttp://www.europarl.europa.eu/news/pt/headlines/society/20170627STO78418/a-reforma-dosistema-europeu-comum-de-asilo>. Acesso em: 14 nov. 2017.

SECRETARIA NACIONAL DE JUSTIÇA. Refúgio em Números. Disponível em: <http://www.acnur.org/fileadmin/scripts/doc.php?file=fileadmin/Documentos/portugues/Publicac oes/2017/refugio-em-numeros-2010-2016>. Acesso em: 19 out. 2017.

SERVICE PUBLIC. Droits du demandeur d'asile: soins, logement, aide financière. Disponível em: < https://www.service-public.fr/particuliers/vosdroits/F32454>. Acesso em: 20 out. 2017.

TRIBALAT, Michèle. Michèle Tribalat: "L'Europe nous a imposé un modèle multiculturel auquel la France n'a jamais vraiment cherché à s'opposer".

Disponível em: <http://www.atlantico.fr/decryptage/michele-tribalat-europe-impose-modelemulticulturel-auquel-france-jamais-vraiment-cherche-opposer-

3069583.html\#yv92Vp8uYrjgHlBz.99>. Acesso em 30 nov. 2017.

VASCONCELLOS, Marcos de. Brasil tem 26 mil pedidos de refúgio e só 13 pessoas para analisá-los. Consultor Jurídico. Disponível em: <https://www.conjur.com.br/2017-abr-14/brasil26-mil-pedidos-refugio-13-pessoas-analisa-los>. Acesso em: 30 nov. 2017. 